\title{
DO INOMINÁVEL AO CIENTIFICAMENTE EXPLÍCITO: MONSTROS LOVECRAFTIANOS
}

Nathalia Sorgon Scotuzzi (UNESP/FCL-Ar) Aparecido Donizete Rossi (UNESP/FCL-Ar)

Recebido em 19 fev 2017. Nathalia Sorgon Scotuzzi possui graduação em História Aprovado em 30 mar 2017. pela Universidade Metodista de Piracicaba (2012) e é mestre em Estudos Literários pela UNESP/FCL-Ar. É membro dos grupos de pesquisa (CNPq/UNESP) Vertentes do Fantástico na Literatura, e (CNPq/UERJ) Estudos do Gótico.

Aparecido Donizete Rossi é professor de literatura inglesa da UNESP - Faculdade de Ciências e Letras de Araraquara, SP. Líder do grupo de pesquisas (CNPq) Vertentes do Fantástico na Literatura e membro do grupo de pesquisas (CNPq) Estudos do Gótico.

E-mail: adrossi@fclar.unesp.br

Resumo: Um dos pontos temáticos da obra de H. P. Lovecraft mais reconhecidos e comentados são seus monstros peculiares e inéditos. Cthulhu, por exemplo, é um dos monstros mais conhecidos da cultura pop dos séculos $X X$ e XXI. Apesar disso, a crítica comumente considera apenas um grupo de seus monstros como paradigma para toda a sua obra: seres gelatinosos e tentaculares, impossíveis de serem descritos com precisão. A intenção desse artigo é demonstrar que Lovecraft apresentou, no percurso de sua carreira, diferentes tipos de monstruosidades, por vezes 
amorfos e inomináveis, mas por outras descritos cientificamente. Pretendemos, assim, elencar cada uma dessas categorias de monstruosidades e analisar suas implicações dentro de cada obra, a partir das reflexões de Luiz Nazário e Noël Carroll.

Palavras-chave: H. P. Lovecraft; Monstro; Cthulhu Mythos; Mal; Ciência.

Abstract: One among H. P. Lovecraft's most renowned and remarked thematic points are his peculiar and unique monsters. Cthulhu, for example, is one of the highlighted monsters in pop culture of the 20th and 21th centuries. However, the critics usually consider only one group of these monsters as a paradigm to Lovecraft's whole work: tentacular and gelatinous beings, whose accurate descriptions are impossible to be made. We intend with this paper to show that Lovecraft presented, during his career, different types of monstrosities, sometimes shapeless and unnamable, and sometimes scientifically described. We intend, therefore, to list each of these monstrous categories and analyze their implications inside each work, based on the thinking of Luiz Nazário and Noël Carroll.

Keywords: H. P. Lovecraft; Monster; Cthulhu Mythos; Evil; Science.

\section{CONCEPÇÕES DE MONSTRO}

Em sua obra de 1983, Da natureza dos monstros, Luiz Nazário procurou esboçar um panorama a respeito das características e funções de monstros e monstruosidades na literatura. Em sua opinião, muito se falava sobre a literatura de horror, mas com pouco foco no monstro em si, ainda que ele fosse um dos elementos cruciais para o gênero. Um dos pontos chave que definem seu argumento é de que um monstro é aquele que não é humano em nenhuma de suas características: "o monstro se define, em 
primeiro lugar, em oposição radical à humanidade ideal" (NAZÁRIO, 1983, p.9). Isso é observado desde sua forma física - deformado, gigantesco, amorfo - até a sua falta de moralidade - ele é a encarnação do Mal. Seu propósito é matar, destruir, destroçar, sem que isso acarrete qualquer implicação moral em sua consciência. "[0] monstro não representa uma dimensão da existência humana, mas uma força da natureza desviada contra a humanidade: é o Mal em estado puro" (NAZÁRIO, 1983, p.20). Um monstro é uma transgressão, uma anomalia no funcionamento do universo. $\mathrm{O}$ mal é parte de nossa cultura, e está ligado tanto ao nosso sofrimento quanto às nossas ações: ele é "necessariamente predicado na existência de seres humanos como agentes morais" (JEHA, 2007, p.13). Não existe moral sem a presença do mal, e uma das formas de manifestarmos nossas inseguranças e medos em relação a ele é por meio da criação de monstros. Quando construídos dentro de um universo literário, servirão como um contraponto em relação aos personagens humanos das obras, estes que terão de lidar com o mal encarnado para evitar a perda ou destruição de sua cultura. Sendo assim, devem ser enfrentados e eliminados pela instância do herói, o que completa a narrativa e retoma a harmonia da trama.

O monstro, dentro de uma obra literária, possui a função de desestabilizar um conjunto de regras pré-definidas, as quais buscam a todo custo serem restauradas pelos personagens envolvidos com a criatura. Assim, o monstro pode ser visto como um elemento que vem perturbar uma ordem para que ela seja não apenas restaurada, mas novamente valorizada. "[D]esde os mitos tribais e arcaicos de heróis civilizadores, cuja tarefa era domesticar e vencer os monstros, a humanidade buscou a afirmação de seu poder na dominação da 
natureza interna e externa a si própria" (NAZÁRIO, 1983, p.9), o que implica que, dentro desses contextos, a ordem "natural" das coisas - civilizada, aculturada, racionalizada, "artificial", portanto - deve ser sempre mantida e qualquer elemento que a perturbe deve prontamente ser eliminado ou absorvido. Esse tipo de monstro que desestrutura a consonância de um enredo e por isso, ou pelo bem da moral, deve ser eliminado é muito comum e recorrente. Podemos encontrá-lo, por exemplo, no Gótico tradicional.

Drácula, o arqui-vampiro, é, por definição, um monstro típico: personifica o puro mal, tem aparência assustadora e procura destruir a vida dos demais personagens com os quais se relaciona. Sua falta de humanidade é a todo tempo enfatizada pelos meandros narrativos. Não faz parte da "natureza" como os personagens a conhecem, e tenta destruí-,los em diferentes níveis: ameaça suas vidas a partir do momento que depende de sangue humano para sobreviver, e também ameaça a moral, já que influencia as ações de diferentes personagens em seu próprio benefício. Por esses motivos, Drácula é tido como um receptáculo do mal, um vilão que deve ser derrotado. Outra figura monstruosa que, junto do pai dos vampiros, complementa essas características é Mr. Hyde, de $O$ médico e o monstro (1886). Grotesco, violento e criminoso, esse ser representa o oposto daquilo que um humano "exemplar" deve ser - entendido "humano exemplar" como o sujeito inteiramente pautado pela ética e moral da sociedade em que vive (neste caso, a vitoriana). Além disso, por ser um duplo do Dr. Jekyll, habitando o mesmo corpo deste, sua monstruosidade é realçada, pois, mais do que uma criatura que aterroriza a ordem natural, ele faz parte do humano, o conceptor da própria ideia de 
"natural". A harmonia da trama só pode ser restaurada quando esse ser abominável não mais existir; todavia, para que ele não mais exista, seu hospedeiro humano também não poderá existir. Erradicar o monstro, neste caso, equivale a erradicar o humano. Monstros que comportam essa dupla chave de configurações são comuns na literatura de horror em geral, em que fantasmas, bruxas, demônios, lobisomens e alienígenas surgem para aterrorizar personagens e destituir a ordem "natural" do mundo empírico e/ou emocional. São tipos recorrentes de monstros que, na maioria das vezes, são derrotados ou mandados de volta para a escuridão de onde nunca deveriam ter saído.

Tais acepções, no entanto, não são suficientes para abarcar todos os tipos de monstros literários, uma vez que são predeterminadas por uma compreensão de Mal inseparável da ideia de moralidade, o que as sedimenta como princípios éticos. Um outro modo de conceber os monstros é entende-los como "criaturas não contempladas pela ciência contemporânea"1 (CARROLL, 1990, p.37 - tradução nossa). Isso não significa que tenham alguma relação com a moralidade e a ética humanas ou mesmo que sejam maléficas. Ademais, "alguns monstros podem ser apenas ameaçadores em vez de aterrorizantes, enquanto outros podem não ser nem ameaçadores nem aterrorizantes"2 (CARROLL, 1990, p.28 - tradução nossa). Essa perspectiva em relação ao monstro se mostra mais abrangente, abrindo-se para outras entidades literárias pertencentes ao campo do

1 "[...] those are understood to be creatures not countenanced by contemporary science".

2 "Some monsters may be only threatening rather than horrifying, while others may be neither threatening nor horrifying". 
desconhecido. Assim, para que um monstro seja amedrontador, ele deve ser perigoso e letal. Porém, isso não significa que esse perigo proposto pelo monstro seja intencional. Pelo contrário, ele é apenas sentido dessa forma pelos personagens da trama. Dentro desse viés, Drácula pode ser concebido como não intencionalmente mal, mas sim um predador do humano que, como qualquer predador, precisa se alimentar. Isso não significa que queira proporcionar sofrimento aos demais personagens.

[E]m obras de horror, os humanos consideram os monstros que encontram como anormais, como distúrbios da ordem natural. [...] Os monstros do horror [...] violam as normas da propriedade ontológica presumida pelos personagens humanos positivos na história ${ }^{3}$. (CARROLL, 1990, p.16 tradução nossa)

É essa violação do que é considerado "natural" que causa o medo e a repulsa em relação ao monstro, e nem sempre ela é necessariamente acompanhada da noção de mal. A reação violenta de personagens humanos contra o monstro ocorre, muitas vezes, antes que o monstro sequer se mostre ruim ou bom. O monstro de Frankenstein, por exemplo, é rechaçado pela sociedade apenas em função de sua aparência exterior. Disforme e visualmente ameaçador, seu aspecto é suficiente para que os personagens o tomem como algo mal. Trata-se, portanto, de uma questão inerente à cultura: aquilo que estamos acostumados, logo, condicionados, ou não a tratar como normal. Monstros são considerados não naturais em relação ao que dada

3 In works of horror, the humans regard the monsters they meet as abnormal, as disturbances of the natural order. [...] The monsters of horror [...] breach the norms of ontological propriety presumed by the positive human characters in the story. 
cultura considera normal: "eles não se encaixam no esquema, o violam. Assim, monstros não são apenas ameaças físicas; são ameaças cognitivas. São ameaças ao senso comum" ${ }^{\prime 4}$ (CARROLL, 1990, p.34 - tradução nossa). Dessa forma, uma criatura que, a princípio, é representada como pura e desconhecedora do bem ou do mal, como o monstro de Frankenstein, é subitamente interpretada como algo horrendo simplesmente pelo fato de que não pertence à ordem "natural" das coisas. É visto como mal, mas está aquém da noção de moralidade. $\mathrm{O}$ que habita para além do conhecimento humano, seja cognitivamente como o monstro acima citado, ou geograficamente, em lugares distantes ou incógnitos, é monstruoso. Criaturas advindas de locais ocultos ou abandonados possuem características tão desconhecidas quanto esses lugares, e consequentemente não fazem parte das categorias de conhecimento social. O desconhecido assusta, e assim é interpretado como monstruoso.

\section{MONSTROS LOVECRAFTIANOS}

Os contos de H. P. Lovecraft são comumente divididos em categorias temáticas, sendo elas o Ciclo dos Sonhos, que inclui as obras que pendem para a fantasia; os contos de horror e o conjunto conhecido como Cthulhu Mythos, que abrange as histórias que possuem como pano de fundo a mitologia criada pelo autor. Os contos desse grupo pertencem também ao horror, todavia, possuem muitos pontos em comum com a ficção científica. $\mathrm{O}$ que todos esses grupos de obras possuem em comum é a presença de monstros, os quais são compostos de modos diferentes.

4 'They do not fit the scheme; they violate it. Thus, monsters are not only physically threatening; they are cognitively threatening. They are threats to common knowledge'. 
Ao Ciclo dos Sonhos pertence a novela $A$ busca onírica por Kadath (The Dream-Quest of Unknown Kadath, 1926/1927), e contos como "Os gatos de Ulthar" ("The Cats of Ulthar", 1920), "Celephaïs" (1922) e "A chave de prata" ("The Silver Key", 1926). As criaturas sobrenaturais presentes nessas obras, como nos contos maravilhosos, pertencem à lógica interna do universo denominado Terra dos Sonhos por Lovecraft, de modo que só podem ser consideradas monstros se contrastadas com os limites da realidade empírica do leitor. Do contrário, é difícil concebê-las como monstros, pois são "naturais" ao universo ficcional em que habitam.

Já os contos de horror do autor apresentam algumas criaturas tradicionais no imaginário gótico. No conto "O modelo de Pickman" ("Pickman's model", 1927) temos a presença de ghouls, criaturas relacionadas a cemitérios e ao consumo de carne humana, comumente associadas aos zumbis. Advindo das mitologias persa e árabe, esse monstro penetrou no imaginário ocidental a partir da tradução de As mil e uma noites, de Galland (1704-1717), tornandose elemento integrante da tradição gótica pelas mãos de William Beckford em seu Vathek (1786). No conto de Lovecraft, a criatura é descoberta pelo narrador-protagonista da história, que constata que seu conhecido, o artista plástico Richard Upton Pickman, mantém contato com essas criaturas que habitam os subsolos de Boston. O monstro, nessa obra, é retratado de forma assustadora e horrenda, e a única reação que o narrador-protagonista consegue ter ao saber de sua existência é a fuga. Entretanto, Pickman não teme tais criaturas. Ao contrário, as pinta e fotografa. Isso porque não as vê como monstros, mas sim como outros seres quaisquer. Esse personagem, apesar disso, acaba sofrendo consequências 
por agir desse modo. Seu gosto pelo grotesco e suas pinturas animalescas fazem com que o resto da sociedade a que pertence - a vitoriana Boston do final do século XIX - o veja como alguém de moralidade duvidosa, uma vez que, dentro desse grupo, aceitar o monstro ou uma atitude monstruosa é inadmissível. Por isso, o próprio Pickman, por fim, acaba se tornando uma espécie de monstro aos olhos de seus conhecidos. Tem-se aqui uma obra na qual a imoralidade maléfica atribuída a um monstro acaba por contaminar um personagem: sem sucesso (ou sem intenção?) de tornar o ghoul menos monstruoso, Pickman acaba tornando-se um monstro ele mesmo.

Outro conto que apresenta um tipo de monstro conhecido - a criatura disforme e ameaçadora, como o monstro de Frankenstein - é "O forasteiro" ("The Outsider", 1921). Preso em uma habitação escura por toda a sua vida, o protagonista dessa história consegue, por fim, ver-se livre e com acesso a outros lugares que nunca adentrou. Ao se deparar com uma festa em um castelo, o personagem surpreende-se com a vasta quantidade de pessoas, com as quais nunca tivera contato antes. Ao adentrar o local, percebe certo distúrbio e por fim observa a causa da celeuma:

Não posso sequer sugerir a sua aparência, pois era um composto de tudo o que é sujo, antinatural, desagradável, anormal e detestável. Era a sombra fantasmagórica da decadência, da antiguidade e da dissolução, o ídolo pútrido e decomposto de uma revelada malsã, a revelação pavorosa daquilo que a terra, por misericórdia, deveria esconder para sempre. Deus sabe que não era desse mundo - ou não mais deste mundo - conquanto, para o meu horror, vi em seus traços carcomidos e ossudos 
uma paródia repugnante e maligna da forma humana, e em suas vestes imundas e desintegradas uma qualidade indizível, que me fez estremecer ainda mais. (LOVECRAFT, 2013, p.211 - grifo nosso)

A criatura monstruosa, como descobrimos ao final do conto, é o próprio narrador-protagonista refletido em um espelho. Nesse conto, Lovecraft funde, em um só personagem, o monstro e o humano que sente repulsa pelo monstro. De maneira similar à criatura de Frankenstein, essa é, relativamente, humana, ainda que disforme e aterrorizante aos olhos de outras pessoas. Como o personagem nunca tivera acesso a seu reflexo, acaba por ter a mesma reação que todos os outros personagens presentes na festa. Não conhecendo sua própria forma, sente repulsa e ódio por aquela imagem, e atribui a ela qualidades maléficas que não condizem, obviamente, com seu interior. Ao utilizar as palavras "antinatural" e "maligna" para descrever o monstro, sobre o qual conhece apenas o exterior e que é ele mesmo, o narrador-protagonista o submete à moralidade e às convenções culturais. Ele é, de fato, antinatural dentro de uma concepção logocêntrica de humano, mas não se pode afirmar que sua aparência implica em malignidade.

Além das figuras góticas mais tradicionais, os contos de horror de Lovecraft por vezes sugerem outros ou novos tipos de monstruosidades. Criaturas descritas como "inomináveis", "indescritiveis" e "indizíveis" são comuns em suas obras. Como técnica ficcional, o que o autor faz, muitas vezes, é tomar como literal a falta de palavras implicada por tais adjetivos. Um bom exemplo para melhor compreender essa categoria de monstros lovecraftianos é o conto "O inominável" ("The unnamable", 1923). 
Narrado em primeira pessoa, trata-se do relato de um episódio vivido pelo protagonista e seu amigo, Joel Manton, o qual é descrito como um homem racional e insensível a assuntos exotéricos. Já o narrador, Carter, é um escritor e entusiasta de assuntos místicos. Sentados em uma lápide no cemitério da cidade onde vivem, os dois personagens passam seu tempo debatendo acerca da possibilidade de existirem coisas "inomináveis", as quais o narrador defende enquanto o outro refuta. Durante a conversa, é introduzida a história de certa criatura inominável que, de acordo com lendas locais, habitava uma antiga mansão anteriormente localizada naquele cemitério. A criatura supostamente vivia no sótão daquela casa, e havia matado e aterrorizado durante séculos. A aparência ou a própria existência de tal monstruosidade é conhecida apenas por meio de fragmentos que o narrador coletou ao longo do tempo.

Tudo está naquele diário ancestral que encontrei; todos os enigmas silenciados e contos furtivos de coisas com olhos deformados que apareciam nas janelas à noite ou em vales desertos junto aos bosques. Alguma coisa agarrou meu ancestral na estrada em um vale escuro, deixando-o com marcas de chifres no peito e de garras como de macaco nas costas, e quando procuraram pegadas na poeira pisoteada, viram as marcas mistas de cascos bipartidos e patas vagamente antropoides. Certa vez um cavaleiro do serviço postal disse ter visto um velho perseguindo e chamando uma assustadora coisa saltitante e inominável em Meadow Hill, nas horas enluaradas pouco antes da manhã, e muitos creram nele. (LOVECRAFT, 2013, p.222) 
Essa descrição acende o interesse de Manton. Porém, para o personagem racional, a criatura poderia não ser uma anomalia demoníaca da natureza, pois, "ele admitiu, para fins do argumento, que algum tipo de monstro inatural tivesse mesmo existido, mas lembrou-se que mesmo a mais horrenda perversão da natureza não precisa ser 'inominável' ou cientificamente indescritível" (LOVECRAFT, 2013, p.223). Para ele, talvez o monstro fosse apenas uma anomalia natural, sem implicações sobrenaturais. Por fim, ambos os personagens são surpreendidos por uma movimentação assustadora abaixo da tumba onde estavam.

No momento seguinte eu fui derrubado do meu banco medonho pela diabólica batida de alguma entidade invisivel de tamanho titânico, mas de natureza indeterminada, derrubado de costas e esparramado no mofo enraizado daquele horrível cemitério, enquanto da tumba vinha um rugido abafado de ofegar e zumbir e minha fantasia populava a escuridão indevassável com legiões miltônicas de danações malformadas. (LOVECRAFT, 2013, p. 225 - grifo nosso)

O personagem, apesar de sentir o ataque e a presença da criatura, não a vê. Ainda assim, supõe que sua natureza seja inconclusiva, já que não reconhece seu atacante nem seu comportamento. Além do ataque, o narrador tira algumas conclusões sobre o possível agressor com base nas lesões deixadas: "Manton tinha dois ferimentos malignos no peito, e alguns cortes menos severos nas costas. Eu não estava ferido seriamente, mas estava coberto de vergões e contusões das mais intrigantes, incluindo a marca de um casco bipartido" (LOVECRAFT, 2013, p.225). A análise de tais feridas, em especial a marca de um casco 
bipartido, leva o narrador - que já era suscetível a acreditar na existência de criaturas inomináveis - a imaginar que fora de fato atacado pelo monstro ancestral. É o racional Manton quem resolve a questão:

- Por Deus, Manton! O que foi aquilo? Essas feridas... Era daquele jeito?

E eu fiquei atordoado para exultar quando ele sussurrou de volta algo que eu mais ou menos esperava:

- Não, não era daquele jeito de forma alguma. Estava em todo lugar... uma gelatina... um lodo... mas ainda tinha formas, mil formas de horror além de minha compreensão. Havia olhos... e uma deformidade. Era o abismo... o vórtice... a última abominação. Carter, era o inominável! (LOVECRAFT, 2013, p.225 - grifo do autor)

O monstro, por fim, é descrito como inominável. Sua forma é indescritivel em um nível que a mente humana não é capaz de conceber. Manton, o personagem racional, tivera finalmente contato com um monstro que excede qualquer tentativa de racionalização. Sua falta de forma física concreta o distancia não só da humanidade, mas de qualquer criatura existente na Terra. Seu ataque incompressível não se assemelha a nada que a natureza já tenha apresentado. Moral e cultura se tornam discutiveis face a tal monstruosidade. Apesar de ter feito mal aos personagens, não há como deduzir que isso tenha sido intencional ou ao menos consciente.

Esse tipo de descrição lovecraftiana é recorrente e, como já dito, intenta compor novos tipos de monstros. Entidades como a de "O inominável" desafiam não só o entendimento dos limites 
culturais e cognitivos da humanidade, mas desarticulam qualquer possibilidade de racionalização a seu respeito. Essa estratégia de criação do monstro usada pelo autor pode ser denominada fusão: "na medida em que forem seres multifacetados, localizáveis em um continuum espaço-temporal inquebrável com uma única identidade, os consideraremos como figuras de fusão"5 (CARROLL, 1990, p.44 - tradução nossa). Ao mesmo tempo, a criatura descrita no conto é muitas coisas e nenhuma. É caracterizada pelo personagem apenas por meio de alusões a imagens diferentes que consegue associar naquele momento. A representação narrativa do monstro, apesar disso, não é compreensível ou descritível, o que torna sua figurativização impossível. O conto termina com essa questão em aberto, e o monstro provavelmente continuará a habitar aquela casa, e também o texto que contém a ambos, pelo tempo que for deixado ali em paz. Esse artifício de aludir ao monstro, mas nunca o descrever realisticamente, é comum em histórias de horror e sua principal função é potencializar o medo. Um monstro, quando oculto, se torna mais amedrontador, pois, além de causar medo, gera uma expectativa que desconcerta o imaginário do leitor no momento em que lhe permite projetar seus próprios medos na criatura indescritivel/inominável ao tentar preencher de significados, aterrorizantes por certo, esses atributos. Quando se mostra o monstro, esse efeito é destruído, e a potencialidade de sua capacidade de horrorizar diminui exponencialmente.

Em boa parte de seus contos, Lovecraft não cria tramas em que o monstro é descoberto e combatido. Essas descobertas são quase

5 "As long as they are composite beings, locatable in an unbroken spatio-temporal continuum with a single identity, we shall count them as fusion figures". 
sempre acidentais e os personagens de Lovecraft não são páreos para os seres amorfos que habitam as tumbas esquecidas pelo tempo. A representação do humano por parte do autor enfatiza a falta de força e insuficiência de poder para combater tais criaturas; por vezes, o humano sequer sobrevive ao colapso mental causado pelo encontro com a monstruosidade. É o que ocorre em $O$ horror de Dunwich (The Dunwich horror, 1929), que traz uma entidade invisível, gigantesca e incompreensível.

\section{AS MONSTRUOSIDADES DO CTHULHU MYTHOS}

Por fim, a última categoria de contos de Lovecraft que apresenta um tipo diferente de monstro é o conjunto Cthulhu Mythos. É importante esclarecer que sob essa denominação incluiremos apenas $\operatorname{contos}^{6}$ que, no entendimento do próprio autor, caracterizamse pelo pressuposto de uma "arte cósmica não sobrenatural" (LOVECRAFT, 2011a, p.119-120 - grifo do autor), ou seja, o tipo de ficção buscado por Lovecraft nos últimos anos de sua vida, o qual se distingue pela presença e desenvolvimento de tramas circunscritas a uma topografia fictícia (Arkham ou a Miskatonic University), presença de criaturas vinculadas a um panteão de "deuses" alienígenas e um compromisso com a descrição "científica" dos fatos, descrição essa por vezes difusa e dependente da instância da personagem. A análise dos contos que preenchem esses requisitos

6 Outras obras aqui não incluídas, apesar de possuírem características desse ciclo e fazerem referências a essas criaturas, servem como complementos a esses textos principais, uma vez que suas tramas se dispersam do objetivo aqui proposto. Entre eles estão: "O assombro das trevas" ("The Haunter of the Dark", 1936), "O horror de Dunwich" (The Dunwich Horror, 1928) e "Dagon" (1917). Esses contos, apesar de serem geralmente considerados parte do Cthulhu Mythos, não serão abordados na presente análise por não corresponderem a todas as características propostas pela ideia de arte cósmica não sobrenatural aqui perseguida. 
permite o levantamento de uma história ficcional do planeta Terra e seus arredores, seus habitantes, passado e presente, além do lugar da humanidade em meio ao cosmos. Quando reunidas, as informações presentes em cada conto permitem o desenho de um panorama que faz com que seus monstros ganhem contornos mais nítidos, porém não menos aterradores. Consideramos obras que apresentam tais características os contos "O chamado de Cthulhu" ("The Call of Cthulhu", 1926), "A cor que caiu do espaço" ("The Color out of Space", 1927), "Um sussurro nas trevas" ("The Whisperer in Darkness", 1930), Nas montanhas da loucura (At the Mountains of Madness, 1931), A sombra de Innsmouth (The Shadow over Innsmouth, 1931) e A sombra vinda do tempo (The shadow out of Time, 1935).

Os monstros apresentados em cada um desses textos, a princípio, são entidades ao mesmo tempo desconhecidas e detentoras da habilidade de causar curiosidade. Em "Um sussurro nas trevas", por exemplo, o narrador-protagonista Albert N. Wilmarth é um acadêmico da Miskatonic University que se vê envolvido em um caso curioso ocorrido no estado de Vermont. Após algumas enchentes fortes, criaturas desconhecidas são encontradas em meio aos destroços. Incógnitas para a população, são interpretadas como seres do folclore local. Essas criaturas, chamadas pela narrativa lovecraftiana de $\mathrm{Mi}$-Go, recebem diferentes tratamentos pelos personagens no curso da trama, sendo, a princípio, apenas criaturas curiosas que chamam a atenção da população. Todavia,

$\mathrm{O}$ que as pessoas jugavam ter visto eram formas orgânicas diferentes de qualquer outra vista até então. Naturalmente, muitos corpos humanos 
foram arrastados pelas corredeiras durante esse trágico período; mas as pessoas que descreviam essas formas estranhas afirmavam ter certeza de que não eram humanas, apenas de algumas semelhanças superficiais no tamanho e no contorno geral. [...] Eram coisas rosadas que mediam cerca de um metro e meio; com corpos crustáceos que ostentavam um enorme par de nadadeiras dorsais ou asas membranosas e diversos membros articulados, providos de uma espécie de elipsoide convoluto, coberto por miríades de antenas curtíssimas onde, em criaturas normais, seria o lugar da cabeça. (LOVECRAFT, 2011b, p.27)

A descrição é a de um provável animal, apenas nunca visto por aquelas pessoas. Considerado talvez como ser que habita furtivamente as montanhas da região, a princípio causa somente curiosidade e não medo. Podemos notar, desde sua primeira aparição, que se trata do monstro explícito. A estratégia de descrevê-lo de forma turva, apenas por meio de sugestões e alusões confusas, como Lovecraft fazia em seus contos anteriores, é posta de lado. Esse novo monstro é concreto, visível, e minuciosa e cientificamente descrito. Se considerarmos a segunda concepção de monstro outrora aventada, de início a criatura é um monstro pelo fato de não ser conhecida pela ciência representada na narrativa, o que a coloca no campo do desconhecido e do intrigante, mas não do assustador ou maligno.

É o desenvolvimento da trama, no entanto, que apresenta essas criaturas mais a fundo e as relaciona com os personagens, resultando na emergência do monstruoso. Após a investigação de Wilmarth junto a outro acadêmico que vive na região (Henry W. Akeley), o fato de que aqueles seres habitam aquelas regiões é confirmado, 
e também há a sugestão de que sejam seres hostis à humanidade. Em um primeiro momento, são reunidas evidências constantes de que os Mi-Go estejam se aproximando da propriedade de Akeley, e seu caráter invasivo fica mais intenso. Protegendo-se com cães e armamento, o personagem acredita que tais seres queiram atacálo. Nesse ponto da trama, a monstruosidade dos Mi-Go finalmente é realçada, pois nuances de maldade são reconhecidas em seus atos pelo personagem: elas são perigosas e parecem querer ferir ou atacar Akeley. Essa é, apesar disso, apenas a opinião dos personagens principais da trama, que analisam essas características sob o ponto de vista tipicamente humano de quem teme o que não conhece. A maldade desses seres é vista a partir da interpretação que os personagens têm de seus atos, porém não há concretização de gestos maléficos em nenhum momento.

Ao fim do conto, a monstruosidade das criaturas que assustam e aterrorizam os personagens é alterada. Primeiramente, realizam contato com Akeley e anunciam quais são suas intenções. Ao contrário de prejudicá-lo, dizem que tudo o que querem é iniciar uma comunicação. Os Mi-Go se apresentam e contam sua história e origens ao personagem, eliminando todas as suspeitas e préconceitos que ele tinha em sua relação. Nesse momento, deixam de ser monstros para ele - e para nós, leitores. Wilmarth, entretanto, não confia nas intenções das criaturas e continua a manifestar suspeitas. Nesse momento, inicia-se um jogo de pontos de vista narrativos que faz as opiniões monstro ou não-monstro oscilarem, dependendo de cada personagem, até o final da trama. Outro elemento que torna oscilante sua monstruosidade é a questão de sua história e ciência. Durante as conversas dos personagens 
com esses seres, é dito que são entes intergalácticos que possuem certos postos no planeta Terra devido a um material orgânico que possuímos e que não existe em seu planeta. Sua ciência é muito mais avançada do que a ciência humana, e isso se mostra de várias maneiras: possuem a capacidade de viajar pelo espaço, possuem aparelhos tecnológicos incompreensíveis aos seres humanos e compreendem o universo de um modo impossível à mente humana. Isso mostra que, apesar de serem seres desconhecidos da ciência são ainda seres naturais e, caso revelados à comunidade científica, começarão a fazer parte do conjunto dos conhecimentos humanos, mesmo que colocando em xeque esses conhecimentos. Essa possibilidade altera o patamar de monstro dessas criaturas, pois permite que elas possam ser aceitas pela ciência. Uma vez que isso ocorra, ainda que no campo das possibilidades imaginárias, a concepção humana de monstro cai por terra.

De fato, a espécie compõe-se de matéria totalmente desconhecida na região do espaço onde nós habitamos - com elétrons que vibram em frequências muito diferentes. É por esse motivo que as criaturas não podem ser fotografadas com os filmes e as chapas tão comuns no universo conhecido, mesmo que os nossos olhos possam vêlas. Com o conhecimento adequado, no entanto, qualquer pessoa versada em química seria capaz de preparar uma emulsão a fim de registrar suas imagens. (LOVECRAFT, 2011b, p.77)

Dentro da segunda acepção de monstro outrora aventada, essas entidades não seriam mais monstros, mas seres naturais, uma vez que cruzam a fronteira entre o desconhecido e o conhecido pela ciência. 
[S]e a ocorrência se torna comum, o fenômeno perde seu aspecto prodigioso e é aceito como natural, ou seja, pertencente à ordem das coisas como as conhecemos. De maneira semelhante, em nossa percepção, quando um fenômeno tende a se repetir, ele se torna 'natural'. (JEHA, 2007, p.22)

Ao longo da trama, os Mi-Go vão se tornando cada vez mais compreensíveis aos personagens e, consequentemente, ao leitor. A explicação esmiuçada de suas intenções, planos e funcionamento de sua ciência vão, a cada página, mostrando que os seres são algo recorrente no Universo - os humanos apenas não os conhecem ainda. Do ponto de vista da primeira acepção de monstro acima aventada, também não podem ser considerados monstros, pois suas intenções foram reveladas e não representam, a princípio, transgressão da moral e da ética. Habitam o planeta apenas para seu próprio proveito, e não querem ferir ou eliminar a humanidade - a menos que esta desfira o primeiro ataque. "[0] monstro só entende a relação selvagem, sem reciprocidade" (NAZÁRIO, 1983, p.80); os monstros do conto em questão, ao contrário, são racionais e inteligentes, e possuem a capacidade de manter um diálogo pacífico com o humano. Ao fim da obra, a impressão geral é de que Lovecraft apresentou diversos argumentos e se valeu de um estilo narrativo específico, o científico-racionalista ou naturalista, para retirar suas criaturas do âmbito da monstruosidade. Elas terminam sendo apenas uma adição à biologia e história da Terra. Não querem o mal da humanidade, e simplesmente a ignoram.

Essa compreensão a respeito dos Mi-Go, como também de outros monstros de Lovecraft, se desenvolve a cada conto em que tais seres são citados. Os personagens desses contos entendem, na 
conclusão de cada narrativa, apenas uma parcela da realidade que os circunda, e muitas vezes esse conhecimento já é suficiente para que vivam atordoados pelo resto de suas vidas. Já para o leitor, um panorama explicativo vai se formando, e ao juntarmos as peças de cada uma dessas tramas podemos aprender a história desses seres e suas implicações para o planeta e a vida humana, de modo que a ideia de monstruosidade vai, pouco a pouco, se tornando difusa, relativa e questionável.

Nas montanhas da loucura, novela que une várias criaturas em uma narrativa intergaláctica, Lovecraft traz novamente os MiGo. Na trama, é narrada a chegada das criaturas ao planeta Terra há milhares de anos e são apresentadas as guerras que travaram com outros monstros de diferentes esferas e seus desfechos. 0 aparecimento dessas criaturas nesse outro trabalho de Lovecraft intenta comprovar, dentro e para os fins do universo ficcional criado pelo autor, a existência desses seres, para o caso de restarem dúvidas de que a história de Wilmarth e Akeley fosse "real". Para tanto, tem-se William Dyer, narrador-protagonista e companheiro de trabalho de Wilmarth. Em alguns momentos da trama, Dyer cita seu colega e afirma não acreditar em suas histórias, porém ao fim de sua aventura ele admite que tudo o que ouvira era verdade. As descobertas de um conto confirmam as descobertas de outros, e assim Lovecraft também sugere que suas criaturas alienígenas pertencentes ao Cthulhu Mythos não são, do ponto de vista da natureza do universo, monstros. Com o jogo de pontos de vista tecido pelo autor, podemos notar que alguns personagens os veem dessa forma, mas isso é ou temporário, até que tenham contato ou os estudem, ou fruto de impressões socioculturais previamente 
negativas devido ao caráter desconhecido desses seres. Lyslei Nascimento, em sua análise dos monstros de Borges, comenta um caso parecido. Ao tecer considerações sobre $O$ livro dos seres imaginários (1957), a autora afirma que

O hipopótamo gigante, ou um elefante, ou ainda um búfalo mítico, citado no livro de Jó e chamado de Beemot, por exemplo, aponta para a monstruosidade como uma questão de ponto de vista. Enquanto para os humanos, presentes na narrativa bíblica, o Beemot apresenta-se como uma fera da natureza híbrida e de origem remota, que, por seu tamanho descomunal, é visto como monstruoso, no discurso do Criador, no entanto, a criatura revela-se uma obra-prima. [...] Assim, esse hipopótamo, elefante ou búfalo, representa a força da natureza, bruta e indomável, que o homem não consegue domesticar, mas que é uma obra-prima pro Criador. (NASCIMENTO, 2007, p.73)

Nos contos que compõem o Cthulhu Mythos, Lovecraft busca deslocar o foco da narrativa do ponto de vista humano para um ponto de vista mais distanciado, crítico se se preferir, em relação a esse humano. Uma das bases de sua estética cosmicista, em suas próprias palavras, seria uma perspectiva indiferentista em relação ao cosmos:

De forma contrária ao que tu possas assumir, não sou um pessimista, mas sim um indiferentista - ou seja, não cometo o erro de pensar que os efeitos das forças naturais que cercam e governam a vida orgânica terão qualquer conexão com os desejos ou gostos de qualquer parte do processo dessa vida orgânica. Pessimistas são tão ilógicos quando otimistas; de tal maneira que ambos contemplam os objetivos da humanidade como unificados, e como tendo uma relação direta (tanto de frustração 
quanto de satisfação) com o fluxo inevitável dos impulsos e eventos terrestres ${ }^{7}$. (LOVECRAFT, 1971, p.39 - grifo do autor - tradução nossa)

Esse modo de enxergar o mundo manifesta-se na concepção dos contos do autor, nos quais narradores e personagens atuam como descobridores de uma porção encoberta da natureza e que nada podem fazer a seu respeito. Eles percebem cada vez mais o quão pouco a humanidade conhece a respeito do mundo ao seu redor, e o quão insignificante somos no panorama universal. A função desses personagens é apenas a de descobrir, porém, de modo irônico, dificilmente compreendem ou conseguem lidar com suas próprias descobertas. A junção dessas descobertas, suas implicações dentro do universo lovecraftiano e suas relações são estabelecidas exclusivamente pelo leitor, que termina cada conto com a sensação de que Lovecraft buscava construir um senso de medo cósmico. Noël Carroll (1990) discute a possível identificação que um leitor pode ter com um personagem, e conclui que o que de fato pode ocorrer é que, apesar de seus sentimentos não serem os mesmos, o leitor irá assimilar a experiência do personagem e compadecer-se de seu sofrimento. Isso acontece quando, por exemplo, Drácula ataca uma de suas vítimas. Esta claramente estará desesperada e aterrorizada, porém não o leitor. O efeito gerado neste é a sensação de apreensão pelo personagem, sem, no entanto, as consequências do terror, pois

7 "Contrary to what you may assume, I am not a pessimist but an indifferentist - that is, I don't make the mistake of thinking that the resultant of the natural forces surrounding and governing organic life will have any connection with the wishes or tastes of any part of that organic life-process. Pessimists are just as illogical as optimists; insomuch as both envisage that aims of mankind as unified, and as having a direct relationship (either of frustration or fulfillment) to the inevitable flow of terrestrial motivation and events". 
eu vejo a situação não apenas do ponto de vista da protagonista, apesar de conhecer esse ponto de vista, mas também pelo lado de fora - vejo como uma situação que envolve um protagonista que tem devido ponto de vista ${ }^{8}$ (CARROLL, 1990, p.95 - tradução nossa).

Essa questão, entretanto, é um pouco diferente quando transposta ao Cthulhu Mythos. Os terrores propostos pela existência desses monstros não são terrores simplesmente físicos (como a mordida de Drácula e a possível morte resultante disso) ou morais (a possibilidade de tornar-se um vampiro, transformando-se assim também em um monstro), mas sim ameaças à existência da raça humana no planeta Terra. Os Mi-Go não têm intenção de atacar seres humanos, mas, caso nós os incomodemos, possuem o poder de devastar nossa existência pelo simples motivo de poderem continuar seus trabalhos em paz. Conforme concebida por Lovecraft, a ameaça é sempre de ordem universal, e, consequentemente, os efeitos gerados no leitor não serão apenas de simples simpatia. Ao término da leitura, ele transportará para a sua realidade extratextual essa sensação de ameaça. Mesmo que não acredite em monstros, o medo de um extermínio - por guerras, por alienígenas, pela própria natureza ou por fatores desconhecidos - não deixa de ser inerente à realidade empírica.

Essa progressão de ajuizamentos sobre os Mi-Go, de acordo com cada personagem e cada momento da trama, que se inicia com a classificação de monstro e finda com a incorporação ao mundo natural ocorre em todos os contos do Cthulhu Mythos mencionados

8 "I see the situation not only from the viewpoint of the protagonist, though I know that viewpoint, but rather, I see it as one who sees the situation from the outside as well-I see it as a situation involving a protagonist who has the viewpoint she has". 
acima, em alguns casos nos enredos e em outros quando em vista do conjunto narrativo desse ciclo literário. A princípio são essencialmente monstros por não se parecerem com seres naturais e conhecidos por representarem alguma ameaça devido à sua condição de alteridade quase absoluta. No entanto, ao fim das tramas a perspectiva é alterada e essas criaturas passam a fazer parte do funcionamento "natural" do universo. Assim como sua forma física, suas origens também são sempre distantes e desconhecidas: os Mi-Go habitam as montanhas inóspitas de Vermont e o planeta Yuggoth (reconhecido ao fim do conto como Plutão); os Elder Ones, introduzidos em Nas montanhas da loucura, vivem no continente antártico; Cthulhu está preso nas profundezas do oceano. Podemos dizer, com base nesses elementos, que tais monstros lovecraftianos são apenas seres ocultados pelo desconhecimento humano sobre seu próprio planeta. Eles não desestabilizam a ordem "natural" das coisas, pois fazem parte dessa ordem; apenas ainda não houve contato, na história humana, com sua presença. Enquanto permanecerem dessa maneira escondidos, esses seres não apresentam perigo à humanidade. Enquanto o ser humano estiver seguro e dentro de suas fronteiras, a ameaça está contida.

\begin{abstract}
[A]s fronteiras existem para manter medida e ordem; qualquer transgressão desses limites causa desconforto e requer que retornemos o mundo ao estado que consideramos ser o certo. 0 monstro é um estratagema para rotular tudo que infringe esses limites culturais. (JEHA, 2007, p.20)
\end{abstract}

O que cada um dos protagonistas lovecraftianos faz é desbravar fronteiras. Inicialmente físicas, ao se deslocarem até lugares distantes e desabitados e o explorarem e, em um segundo momento, culturais, ao se depararem com criaturas até então desconhecidas e 
que transgridem muito do que se conhece a respeito da natureza e seu funcionamento. Após tais descobertas, o que esses personagens fazem é retornar imediatamente à segurança de suas cidades e deixar esses locais que exploraram novamente abandonados. O choque causado pelas novidades que encontram causa o efeito imediato de necessidade de um retorno à ordem. Apesar dessa tentativa, suas consciências já não são mais as mesmas, pois tornaram-se diversas pelo contato com a diferença:

Toda vez que ampliamos nosso domínio epistemológico, quer conquistando novos territórios, quer desbravando-os, as fronteiras que controlam nossas vidas também se movem [...]. O mesmo acontece quando descobrimos ou inventamos algo: nossa visão de mundo tem de acomodar outros seres ou novos fenômenos e isso pode causar incerteza epistemológica. Nossa experiência se baseia em fundamentos epistemológicos e ontológicos; mudanças epistemológicas vão gerar alterações ontológicas, e um acréscimo ontológico vai forçar nosso conhecimento a se expandir. Quando isso ocorre, sentimos que nossas expectativas de ordem - as fronteiras - estabelecidas pela ciência, filosofia, moral ou estética, foram transgredidas. E transgressões geram monstros. (JEHA, 2007, p.21)

Apesar de se encontrarem novamente em segurança dentro de suas fronteiras físicas - , esses personagens têm seus conhecimentos expandidos. Querendo ou não, agora devem lidar com a realidade da existência das entidades que, por serem transgressoras da natureza na configuração em que estão acostumados, são vistas por eles como monstros. A ideia dos MiGo é aterrorizante para Wilmarth e ele os vê dessa forma, pois 
transgridem muito do que ele tomava por real. Ele sabe, apesar disso, que esse medo que sente e esses atributos monstruosos que atribui a esses seres são frutos de sua irracionalidade. Ao analisá-los racionalmente, compreende melhor sua natureza. Ele os teme não por serem monstros incompreensíveis, mas por serem predadores em potencial.

Além de notarmos uma relativização da figura monstruosa entre a perspectiva dos personagens e a perspectiva indiferentista de universo que Lovecraft busca construir, podemos observar diferenças entre a forma com que cada tipo de personagem se refere às criaturas dentro dos contos. Cthulhu é o melhor exemplo para essa questão. Na narrativa de "O Chamado de Cthulhu", diferentes personagens têm contato com esse monstro. Para os povos que o cultuam em ritos bestiais, Cthulhu é um deus. Seu grande poder e proporções apocalípticas causam admiração desse grupo, que o venera. Já para os marinheiros que o encontram acidentalmente em meio ao oceano, despertando de sua tumba, Cthulhu é um verdadeiro monstro. A esses personagens não é dado tempo de compreender o que estão vendo, pois enlouquecem no imediatismo do contato, de modo que, para eles, Cthulhu é a própria manifestação do Mal. Já o narrador-protagonista do conto, após extensa pesquisa a respeito da criatura, que inclui os relatos dos personagens citados anteriormente, consegue vislumbrar uma possibilidade de realidade desse ser. Ele conta, de início, com a pesquisa previamente feita por seu tio, um acadêmico da Miskatonic University e homem de boa reputação. Esse contato inicial com os fatos que irá coletar durante a trama faz com que, desde o começo, sua posição em relação aos acontecimentos seja 
racional. Em meio aos documentos do tio, encontra uma estatueta em baixo relevo de uma criatura que nunca vira ou imaginara antes, a reprodução de um artista que vira Cthulhu em seus sonhos. Estatueta semelhante é encontrada em meio ao ritual dos seguidores do monstro, e ele é descrito da mesma maneira pelos marinheiros. A junção dessas evidências faz com que o narrador-protagonista ateste a existência da criatura e permite, em um laivo contraditoriamente moralizante, que compreenda que a natureza esconde coisas do ser humano que de fato devem permanecer ocultas.

A coisa mais misericordiosa do mundo é, segundo penso, a incapacidade da mente humana em correlacionar tudo o que sabe. Vivemos em uma plácida ilha de ignorância em meio a mares negros de infinitude, e não fomos feitos para ir longe. As ciências, cada uma empenhando-se em seus próprios desígnios, até agora nos prejudicaram pouco; mas um dia a compreensão ampla de todo esse conhecimento dissociado revelará terriveis panoramas da realidade e do pavoroso lugar que nela ocupamos, de modo que ou enlouqueceremos com a revelação ou então fugiremos dessa luz fatal em direção à paz e ao sossego de uma nova idade das trevas. (LOVECRAFT, 2012, p.97 - grifo nosso)

O narrador deixa claro que, em sua opinião, Cthulhu não é um monstro ou ser sobrenatural, mas sim uma criatura da natureza que permanece encoberta a nossos olhos. Para ele, Cthulhu é parte de nossa realidade e pode ser descoberto e talvez explicado pela ciência. Ele acredita que o fato de isso não ter acontecido ainda é uma vantagem à humanidade, pois essa descoberta talvez seja demais para a mente humana. Ela acabaria com a imagem de 
que somos significantes e nos atiraria ao caos. Por fim, o último ponto de vista a respeito de Cthulhu será formulado pelo leitor, o qual estará inclinado, se aceitar os argumentos do narrador, a acreditar que Cthulhu é uma criatura poderosa e natural, que habita contra sua vontade um determinado local em nosso espaço. Unindo a esse conto os detalhes e menções a Cthulhu de outras histórias, essa impressão é enfatizada. Nas montanhas da loucura, além de se relatar a chegada dos Mi-Go à Terra, há também o relato da chegada de Cthulhu. Novamente, essa novela confirma dados de outro conto, gerando, na mente do leitor, o efeito de veracidade e naturalidade desses seres dentro da arquitetura do universo ficcional.

Lovecraft constrói um senso de apreensão que perdura após seus contos, senso esse de que, apesar de a humanidade estar segura no presente momento, ela pode ser devastada caso algum desses seres decida tomar o planeta. Porém, eles não fariam isso por maldade ou qualquer outra intenção negativa para com o ser humano, mas sim porque se beneficiariam de alguma forma, como qualquer predador. Lovecraft desloca as questões de moralidade relacionadas aos monstros em contos de horror, que geralmente são focados em protagonistas ou grupos de personagens, para questões de cunho existencialista. Caso seu monstro se manifeste, não será um ataque direcionado a um personagem, mas sim à existência humana. Assim, para a humanidade representada nos contos, seus monstros nunca deixarão por completo de serem monstros, apesar de todo o processo de desarticulação empreendido pelo autor para mostrar que são apenas seres naturais compartilhando o planeta conosco. 
Ainda no início do século XX, Lovecraft antecipou temas que não eram discutidos pela literatura de sua época. As narrativas fantásticas contemporâneas a seus contos apresentavam um teor mais otimista em relação ao ser humano e seu futuro. Narrativas marcianas, por exemplo, preenchiam as revistas pulp da época com aventuras intergalácticas protagonizadas por heróis desbravadores que asseguravam um futuro pacífico à humanidade. Em contrapartida, Lovecraft populava o recém-descoberto Plutão com seus monstros amorais. Enquanto romances, contos e filmes utilizavam a metáfora do extraterrestre para manifestar os medos e reafirmar a soberania humana, Lovecraft expressava suas dúvidas em relação a essa soberania. A literatura fantástica só viria a tratar do fim da humanidade algumas décadas após a morte do autor. Lovecraft, durante o percurso de sua carreira, utilizou-se de monstros conhecidos, pesadelos de sua mente e seres oriundos de especulação científica para criar um novo patamar de monstruosidade, um patamar que inclui seres que são, ironicamente, tão devastadores quanto naturais.

\section{REFERÊNCIAS}

CARROLL, Noël (1990). The philosophy of horror or Paradoxes of the heart. London; New York: Routledge.

JEHA, Julio (2007). "Monstros como metáforas do mal". In: (orgs.). Monstros e monstruosidades na literatura. Belo Horizonte: Editora da UFMG, p.9-31.

LOVECRAFT, Howard Phillips (2012). O chamado de Cthulhu e outros contos. São Paulo: Hedra.

(2013). "O forasteiro". In: O mundo fantástico de H.P. Lovecraft: Antologia - contos, poesias e ensaios. Jundiaí, SP: Editora Clock Tower. 
(2011a). Nas montanhas da loucura. São Paulo: Hedra. (2011b) Um sussurro nas trevas. São Paulo: Hedra.

NASCIMENTO, Lyslei (2007). Monstros no arquivo: esboço para uma teoria borgiana dos monstros. In: JEHA, Julio (org.). Monstros e monstruosidades na literatura. Belo Horizonte: Editora da UFMG, p.61-80.

NAZÁRIO, Luiz. Monstros marcianos (2007). In: JEHA, Julio (orgs.). Monstros e monstruosidades na literatura. Belo Horizonte: Editora da UFMG, p.146-183. . (1983). Da natureza dos monstros. São Paulo: Edição do Autor. 